\title{
Reduced Fluorescence Quenching of Cyclodextrin-Acetylene Dye Rotaxanes
}

Jong S. Park ${ }^{\dagger}$, James N. Wilson ${ }^{\ddagger}$, Kenneth I. Hardcastle ${ }^{\star}$, Uwe H. F. Bunz ${ }^{\star \ddagger}$, Mohan Srinivasarao*\$\$

${ }^{\dagger}$ School of Polymer, Textile and Fiber Engineering, ${ }^{*}$ School of Chemistry and Biochemistry, ${ }^{8}$ Center for Advanced Research in Optical Microscopy (CAROM), Georgia Institute of Technology, Atlanta, GA 30332; ' Department of Chemistry, Emory University, 1515 Pierce Drive, Atlanta, GA 30322

Correspond to; uwe.bunz@chemistry.gatech.edu, mohan@ptfe.gatech.edu

\section{Supporting Information}

\section{Experimental details}

1.1. Preparation of acetylene dye rotaxane. Synthetic scheme is shown below (Scheme S1).
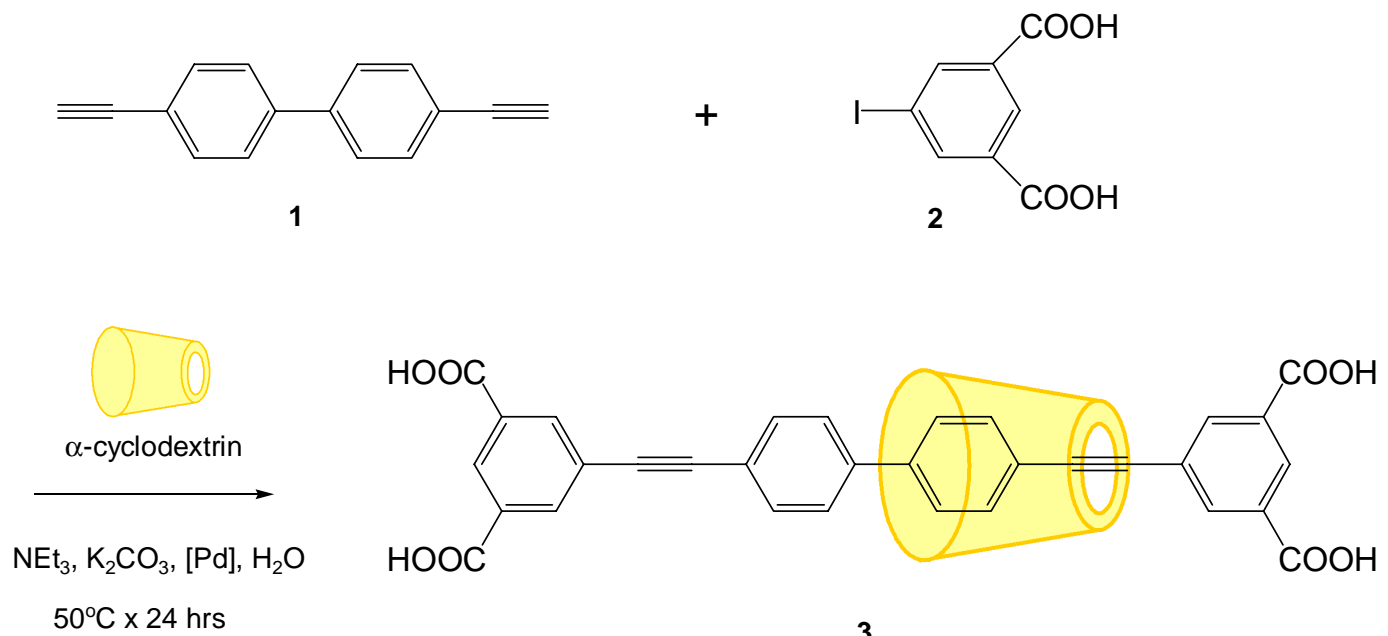

3

Scheme S1. Synthesis of acetylene dye rotaxane.

4,4'-diethynylbiphenyl (1): 4,4'-Diiodobiphenyl (10 g, 24.6 mmol) was dissolved in THF (50 $\mathrm{ml})$ with piperidine $(5 \mathrm{~mL}),\left(\mathrm{Ph}_{3} \mathrm{P}\right)_{2} \mathrm{PdCl}_{2} 0.35 \mathrm{~g}(0.5 \mathrm{mmol}), \mathrm{CuI} 0.475 \mathrm{~g}(2.5 \mathrm{mmol})$, and 
trimethylsilylacetylene $8.7 \mathrm{ml}(61.6 \mathrm{mmol})$ was slowly added under nitrogen. The mixture was warmed up a little bit, and then stirred overnight at room temperature. Then, excess hexane was added and all salts including Pd catalyst were removed by filtering the mixture through silica gel. The filtrate was collected, then evaporated. The residue was dissolved in methanol (1 L) and purified by recrystallization, to collect the precipitate. To remove the silyl protection groups, the filtrate was dissolved in ethanol $(500 \mathrm{~mL})$ in the presence of $\mathrm{KOH}(10 \mathrm{~g})$, and stirred overnight. Two-thirds of solvent was removed by evaporation, and gradual addition of water gave a pale brownish precipitate. It was extracted using methylene chloride several times. Removal of the solvent gave the product 1 (4.48 g, yield 90\%). ${ }^{1} \mathrm{H}$ NMR $\left(300 \mathrm{MHz}, \mathrm{CDCl}_{3}\right): \delta_{\mathrm{H}}=7.4(\mathrm{~b}, 8 \mathrm{H})$, $3.1(\mathrm{~s}, 2 \mathrm{H}),{ }^{13} \mathrm{C}$ NMR $\left(125 \mathrm{MHz}, \mathrm{CDCl}_{3}\right): \delta_{\mathrm{C}}=136.3,132.6,127.0,121.2,84.0,79.0 . \mathrm{m} / \mathrm{z}$ (negative MALDI-TOF) $201.1\left(\mathrm{M}^{-}\right)$.

5-iodo-isophthalic acid (2): Previous report was followed for its synthesis ${ }^{12}$. 5aminoisophthalic acid $(1.75 \mathrm{~g}, 9.6 \mathrm{mmol})$ was suspended in mixture of water $(5 \mathrm{ml})$ at $0-5{ }^{\circ} \mathrm{C}$. Dilute $\mathrm{HCl}(10 \%, 30 \mathrm{ml}, 30 \mathrm{mmol})$ and $\mathrm{NaNO}_{2}(701 \mathrm{mg}, 10.1 \mathrm{mmol})$ solutions were added successively, and then the solution was stirred for $1 \mathrm{hr}$ to complete diazotization. Then small amount of sulfamic acid was added to remove excess nitrite. KI (6.37 g, $38.4 \mathrm{mmol})$ was slowly added, and the mixture was stirred overnight at room temperature. After reaction, the precipitate was collected by filtration, washed with water several times, and dried in vacuo. 1H NMR (300 $\left.\mathrm{MHz}, \mathrm{CDCl}_{3}\right): \delta_{\mathrm{H}}=8.8(\mathrm{~b}, 3 \mathrm{H}),{ }^{13} \mathrm{C} \mathrm{NMR}\left(125 \mathrm{MHz}, \mathrm{CDCl}_{3}\right): \delta_{\mathrm{C}}=172.0,144.5,132.0,130.0$, 98.0. $\mathrm{m} / \mathrm{z}$ (negative MALDI-TOF) $291.0\left(\mathrm{M}^{-}\right)$.

Acetylene dye rotaxane (3): The mixture of 4,4'-diethynylbiphenyl 1 (0.151 g, $0.75 \mathrm{mM})$, triethylamine $0.0 .46 \mathrm{~g}(4.5 \mathrm{mM})$ and $\alpha$-cyclodextrin $(2.92 \mathrm{~g}, 3.0 \mathrm{mM})$ was suspended in water (10 ml). 5-iodoisophthalic acid $2(0.64 \mathrm{~g}, 2.2 \mathrm{mM})$ with potassium carbonate $(0.91 \mathrm{~g}, 6.6 \mathrm{mM})$ in water $(5 \mathrm{ml})$ were slowly added, and the resultant mixture was sonicated for 1 hour under nitrogen. Palladium acetate (11 mg, $0.05 \mathrm{mM}), 3,3$, 3"'-phosphinidynetris(benzene sulfonic acid) 
trisodium salt (29 mg , $0.05 \mathrm{mM})$ and copper iodide $(48 \mathrm{mg}, 0.25 \mathrm{mM})$ were added with stirring.

The mixture was warmed up to $50{ }^{\circ} \mathrm{C}$, and then stirred for a day. After reaction, the mixture was diluted with aqueous $\mathrm{Na}_{2} \mathrm{CO}_{3}$ solution $(2 \mathrm{M}, 50 \mathrm{~mL})$, and then filtered. The filtrate was collected and acidified to below $\mathrm{pH} 1$ with dilute $\mathrm{HCl}$. Soxhlet extraction was done using acetone for 3 days in order to remove remaining starting materials and/or free dye. The dye rotaxane 3 (RD hereafter) was obtained by filtration, washed profusely with water and dried in vacuo overnight. The product was obtained as a pale yellow powder (132 mg, yield $13 \%) . \delta_{\mathrm{H}}(300 \mathrm{MHz}, \mathrm{DMSO})$ $\delta=8.46(\mathrm{t}, 1 \mathrm{H}), 8.45(\mathrm{t}, 1 \mathrm{H}), 8.28(\mathrm{~d}, 2 \mathrm{H}), 8.04(\mathrm{~d}, 2 \mathrm{H}), 7.91(\mathrm{~d}, 2 \mathrm{H}), 7.80(\mathrm{~m}, 4 \mathrm{H}), 7.70(\mathrm{~d}$, 2H), $5.28(\mathrm{~s}, 6 \mathrm{H}), 5.27(\mathrm{~s}, 6 \mathrm{H}), 4.75(\mathrm{~d}, 6 \mathrm{H}), 4.33(\mathrm{~s}, 6 \mathrm{H}), 3.8-3.2(\mathrm{~m}, 36 \mathrm{H}) ; \delta_{\mathrm{C}}(125 \mathrm{MHz}$, DMSO): $\delta=165.6,140.8,139.8,135.0,134.4,133.0,131.8,129.2,127.3,125.5,123.0,120.4$, 119.8, 101.7, 90.9, 90.6, 87.7, 87.3, 81.1, 72.8, 71.9, 59.1 ppm; m/z (ESI- MS) $1501\left(^{-}\right)$. Free dye (FD hereafter) was synthesized following the same routes, but without the addition of $\alpha$-CD. It was purified by dissolving in concentrated absolute ethanol, and then precipitating by small amount of water. It was repeatedly dissolved in aqueous $\mathrm{Na}_{2} \mathrm{CO}_{3}$ solution $(2 \mathrm{M}, 50 \mathrm{~mL})$, and then precipitated in acidic condition, as a pale yellow powder $(170 \mathrm{mg}$, yield $50 \%) . \delta_{\mathrm{H}}(300$ MHz, DMSO) $\delta=8.45(\mathrm{t}, 2 \mathrm{H}), 8.27(\mathrm{~d}, 4 \mathrm{H}), 7.8(\mathrm{~d}, 4 \mathrm{H}), 7.7(\mathrm{~d}, 4 \mathrm{H}) ; \delta_{\mathrm{C}}(125 \mathrm{MHz}, \mathrm{DMSO}): \delta$ $=165.6,139.4,135.4,132.2,129.6,126.8,123.2,121.1,90.6,88.3 \mathrm{ppm} ; \mathrm{m} / \mathrm{z}\left(\mathrm{ESI}^{-} \mathrm{MS}\right) 529$ $\left(\mathrm{M}^{-}\right)$.

1.2. Fluorescence Properties. The fluorescent spectra were collected using a Shimadzu RF5300PC spectrofluorophotometer. Emission spectra were obtained with excitation at $330 \mathrm{~nm}$, if not specified otherwise. For quantum yield determination, a solution of quinine sulfate in $0.1 \mathrm{~N}$ $\mathrm{H}_{2} \mathrm{SO}_{4}$ was used as a reference. The concentrations were adjusted such that the absorbance was around 0.05 . The area of the emission spectrum was calculated from the program and then 
compared to provide an estimate of the quantum yield using the following equation: $\Phi_{s}=\Phi_{r}\left(A_{r} F_{s} / A_{s} F_{r}\right)\left(n_{s}{ }^{2}\right)\left(n_{r}{ }^{2}\right)$, where, $\Phi_{s}=$ quantum yield of the sample, $\Phi_{r}=$ quantum yield of the reference $\left(\Phi_{r}=0.54\right), A_{r}=$ absorbance of the reference, $F_{s}=$ integrated fluorescence intensity of the sample, $A_{s}=$ absorbance of the sample, $F_{r}=$ integrated fluorescence intensity of the reference, $n_{s}=$ refractive index of solvent, and $n_{r}=$ refractive index of $0.1 \mathrm{~N} \mathrm{H}_{2} \mathrm{SO}_{4}$ solution $\left(n_{r}=1.35\right)$. Absorption spectra were measured on a Lambda 7 spectrometer (Perkin Elmer) in 1 cm cuvette. A Headway Research model PWM32 instrument was used to spin-coat dilute ethanol solutions of dyes onto glass slides for thin film measurements. For fluorescence quenching experiments with various metal ions, both $\mathrm{FD}$ and $\mathrm{RD}$ were prepared at a concentration of $1.0 \times 10^{-6} \mathrm{M}$ in HEPES (4-(2-hydroxyethyl)-1-piperazineethanesulfonic acid) pH 7.2 buffer solutions with $10 \mathrm{mM}$ buffer strength. Buffer solutions with various pHs are prepared, using acetate ( $\mathrm{pH} 3.5 \sim 5)$, phosphate ( $\mathrm{pH}$ 6 9), and ethanolamine (above $\mathrm{pH} 9$ ) buffer, respectively, and buffer concentration is maintained at $10 \mathrm{mM}$.

\section{Fluorescence measurements}

There is no significant difference in the electronic absorption and emission spectra of these dyes. With rotaxanation, RD shows a slight red shift in solution, compared with free dye (for $\mathrm{FD}$ and $\mathrm{RD}, \lambda_{\max }(\mathrm{abs})=$.326 and $327 \mathrm{~nm} ; \lambda_{\max }(\mathrm{emi})=367,$.387 and $369,388 \mathrm{~nm}$ in methanol, respectively, Figure S1a). It was known that rotaxane encapsulation stabilized the dumbell in both ground and excited states by protecting the threaded chromophore, ${ }^{3}$ which is considered to be responsible for a slight red shift of RD. In the solid state, however, the emission spectrum of RD exhibits a different behavior. When spin-cast on the glass slide, RD shows a slight blue shift with a narrowing of the absorption peak (Figure S1b). CD encapsulation is known to reduce aggregation of rigid and planar molecules. ${ }^{5}$ As a result, RD shows decreased 
amount of aggregation, compared to FD, in the solid state. These separated dye molecules of RD can lead to a blue shift in their emission. Also CD cavity allows more rotation of a dye moiety even in the solid state, which may be responsible for blue shift in emission to some degree.
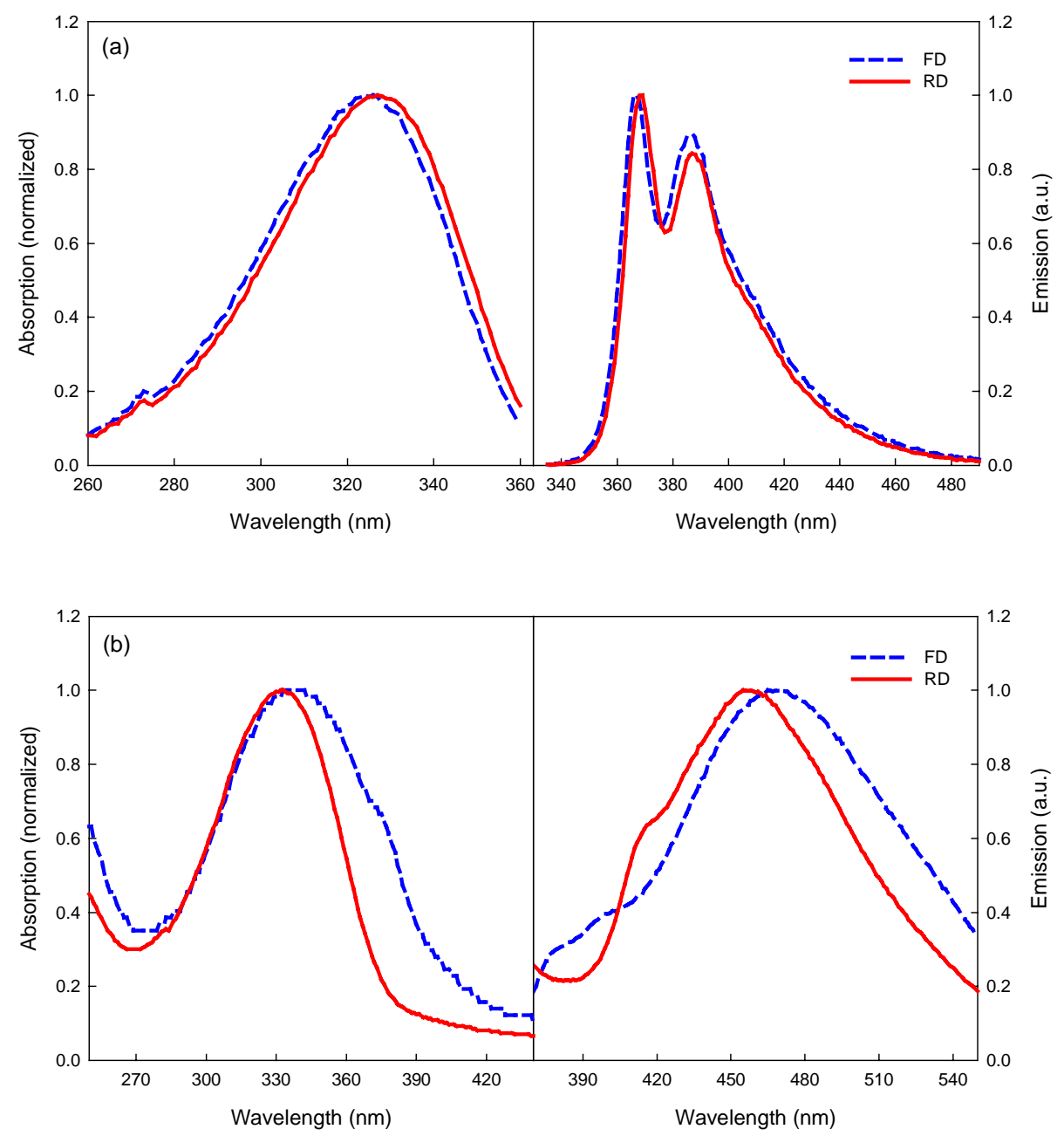

Figure S1. Normalized absorption spectra (left) and emission spectra (right) of FD (blue dotted) and RD (red solid); (a) in methanol, (b) in the solid-state thin film. Emission was obtained with excitation at $330 \mathrm{~nm}$.

The relative fluorescence quantum yields in aqueous buffer and methanol are listed in Table S1. In both solvents, the fluorescence quantum yields of RD are higher than those of FD. This result is not so surprising, since several papers have already reported that CD encapsulation acts as a way of reducing the quenching effect of a surrounding environment and reducing the flexibility of the threaded chromophore, thus leading to an enhancement in quantum yield. ${ }^{1,4}$ 
Table S1. Relative fluorescence quantum yields of FD and RD in aqueous buffer solution and methanol ${ }^{1)}$.

\begin{tabular}{ccc}
\hline Solvent & FD & RD \\
\hline Methanol & 0.554 & 0.669 \\
Aqueous Buffer $^{2)}$ & 0.548 & 0.632 \\
\hline
\end{tabular}

1) Quinine sulfate in $0.1 \mathrm{~N}$ sulfuric acid was used as standard. Absorbance was adjusted at 0.05 $\pm 0.01,{ }^{2)}$ Ethanolamine buffer ( $\left.\mathrm{pH} 9.6\right)$, buffer concentration $10 \mathrm{mM}$.

Important crystal data are listed in Table $\mathrm{S} 2$.

Table S2. Crystal data and structure refinement for RD 3.

\begin{tabular}{|c|c|}
\hline Empirical formula & C68 H78 O40.92 \\
\hline Formula weight & 1550.10 \\
\hline Temperature & $173(2) \mathrm{K}$ \\
\hline Wavelength & $0.71073 \AA$ \\
\hline Crystal system & Monoclinic \\
\hline Space group & $\mathrm{P} 2(1)$ \\
\hline Unit cell dimensions & $\begin{array}{c}a=13.580(2), b=22.798(4), c=23.880(4) \AA \\
\alpha=90^{\circ}, \beta=98.241(4)^{\circ}, \gamma=90^{\circ}\end{array}$ \\
\hline Volume & $7317(2) \AA^{3}$ \\
\hline $\mathrm{Z}$ & 4 \\
\hline Density (calculated) & $1.407 \mathrm{Mg} / \mathrm{m}^{3}$ \\
\hline Absorption coefficient & $0.118 \mathrm{~mm}^{-1}$ \\
\hline Crystal size & $0.36 \times 0.22 \times 0.13 \mathrm{~mm}^{3}$ \\
\hline Theta range for data collection & 1.52 to $23.53^{\circ}$ \\
\hline Index ranges & $-15 \leq h \leq 15,-25 \leq k \leq 25,-26 \leq l \leq 26$ \\
\hline Reflections collected & 46811 \\
\hline Max. and min. transmission & 1.00 and 0.428476 \\
\hline Absorption correction & Semi-empirical from equivalents \\
\hline Refinement method & $\begin{array}{c}\text { Full-matrix least-squares on } \mathrm{F}^{2} \\
\text { (Full-matrix least-squares on } \mathrm{F}=1.022 \text { ) }\end{array}$ \\
\hline Final $R$ indices $[I>2 \sigma(I)]$ & $\mathrm{R}_{1}=0.1961, \mathrm{R}_{\mathrm{w} 2}=0.4422$ \\
\hline $\mathrm{R}$ indices (all data) & $\mathrm{R}_{1}=0.2472, \mathrm{R}_{\mathrm{w} 2}=0.4764$ \\
\hline
\end{tabular}

There are two cyclodextrin and two dye molecules per asymmetric unit, with around 700 atoms per unit cell. And there is disorder in one of the dye molecules. Only the higher occupancy coordinates are plotted in Figure 2. 
Table S3. Emission lifetimes of bisphenylethynylbenzenes taken from literature

\begin{tabular}{cccccc}
\hline Structure & $R$ & $X$ & $Y$ & $\tau(n s)$ & Solvent \\
\hline & $\mathrm{H}$ & $\mathrm{H}$ & $\mathrm{H}$ & $\begin{array}{c}0.64^{\mathrm{a}} \\
0.57^{\mathrm{b}} \\
0.6^{\mathrm{b}}\end{array}$ & $\begin{array}{c}\text { Chloroform } \\
\text { Hexane } \\
\text { MeCN }\end{array}$ \\
\cline { 2 - 7 } & $\mathrm{H}$ & $\mathrm{MeS}$ & $\mathrm{CN}$ & $\begin{array}{c}0.68^{\mathrm{b}} \\
1.8^{\mathrm{b}}\end{array}$ & $\begin{array}{c}\text { Hexanes } \\
\text { MeCN }\end{array}$ \\
\hline
\end{tabular}

a) Birckner, E.; Grummt, U.-W.; Göller, A. H.; Pautzsch, T.; Egbe, D. A. M.; Al-Higari, M.; Klemm, E. J. Phys. Chem. A 2001, 105, 10307-10315. b) Biswas, M.; Nguyen, P.; Marder, T. B.; Khundkar, L. R. J. Phys. Chem. A 1997, 101, 16897-1695. c) Collings, J. C.; Parsons, A. C.; Porres, L.; Beeby, A.; Basanov, A. S.; Howard, J. A. K.; Lydon, D. B.; Low, P. J.; Fairlamb, J. S.; Marder, T. B. Chem. Commun. 2005, 2666-2668. d) Sun, S.-S.; Lees, A. J. J. Photochemistry, Photobiology A, 2001, 140, 157-161. 